\title{
Moral Behavior in the Locker Room Predicts Perceptions of Task Cohesion in Youth Ice Hockey Players
}

\author{
by \\ Scott A. Graupensperger ${ }^{1,2}$, Marie S. Tisak ${ }^{3}$
}

\begin{abstract}
Task cohesion (i.e., perceptions of team unity towards a task goal and positive feelings towards one's own involvement) is associated with myriad psychosocial benefits for youth athletes. Accordingly, sport researchers and youth sport stakeholders are interested in ways of fostering task cohesion. Recent work has found evidence that prosocial and antisocial behaviors among teammates are associated with athletes' perceptions of task cohesion; however, this research has been limited to moral behavior that takes place during gameplay. Despite youth sport experiences extending well beyond practices and games, we know very little about how moral behavior between teammates, in settings outside gameplay, relates to perceptions of task cohesion. To address this knowledge gap, the current study investigated whether prosocial and antisocial behaviors in the locker room setting were associated with perceptions of task cohesion in a sample of 238 youth male ice hockey players ( $\left.M_{\text {age }}=10.75\right)$. Using hierarchical regression analyses, our results revealed that (a) perceptions of peer prosocial behavior was positively associated with task cohesion, (b) perceptions of peer antisocial behavior was negatively associated with task cohesion, and (c) self-reported perceptions of participants' own moral behavior was not significantly associated with task cohesion. Given the association with perceptions of task cohesion, these findings underline the value in promoting prosocial behavior and reducing antisocial behavior in sport settings outside gameplay and hold multiple theoretical and practical implications. Notably, moral behavior that takes place outside gameplay settings may be related to perceptions of task cohesion that primarily relates to goals and interactions during gameplay.
\end{abstract}

Key words: youth sport, group dynamics, prosocial behavior, antisocial behavior, adult supervision.

\section{Introduction}

Beyond the physical benefits, sport participation enables youth to make meaningful connections with a peer-group, where they can learn teamwork and cooperation skills (Carron et al., 2012; Martin et al., 2012). One form of peerconnectedness that pertains to team-sport participation is perceived group cohesion, which reflects unity surrounding task and social needs of the group (Carron et al., 2012; Eys et al., 2009). Because of evidence that cohesion is related to numerous aspects of positive youth development (i.e., personal and social skills; Bruner et al., 2014), youth sport coaches and other stakeholders are interested in building team cohesion. Despite evidence that team cohesion is associated with constructive personal outcomes, there is still much to be learned about antecedents of cohesion for youth sport athletes.

Recent sport literature has found evidence that group processes are linked to moral behaviors between teammates (e.g., Benson and Bruner, 2017). Moral behaviors are intentional acts that have beneficial or harmful consequences for others - entailing both prosocial and antisocial dimensions (Kavussanu and Stanger, 2017). In line with the social cognitive theory of moral thought and action (Bandura, 1991), the significance of a moral behavior lies in the consequences that the

1 - The Pennsylvania State University, Department of Kinesiology, USA.

2 - The Pennsylvania State University, Clinical and Translational Science Institute, USA.

3 - Bowling Green State University, Department of Psychology, USA. 
behavior has on others. For example, supportive behavior from a teammate can have positive consequences for young athletes, while verbal abuse can have negative consequences (Kavussanu and Stanger, 2017). Specifically, Kavussanu and Boardley (2009) argue that prosocial behavior towards teammates can enhance the recipient's motivation and performance, whereas antisocial behaviors can have negative psychological consequences. Furthermore, Benson and Bruner (2017) found that day-to-day variance in teammates' prosocial and antisocial behaviors were associated with youth athletes' perceptions of psychological ties with teammates (i.e., social identity), and the general positive or negative feelings derived from sport team membership.

Specific to team cohesion, sport groupdynamics researchers have argued that positive teammate interactions, such as encouragement and helping, facilitate perceptions of unity and cohesion (e.g., Eys et al., 2009). Recent empirical research found evidence that moral behavior among teammates during gameplay predicted perceptions of task cohesion (Al-Yaaribi and Kavussanu, 2017). Task cohesion is one dimension of group cohesion that refers specifically to individual perceptions of unity surrounding the team's task goals and objectives, and the affective feelings associated with personal involvement in these goals and objectives (Carron et al., 1985). Specifically, Al-Yaaribi and Kavussanu (2017) found that prosocial behavior positively predicted task cohesion, and antisocial behavior negatively predicted task cohesion. While this finding extends understanding of the association between moral behavior and task cohesion, it only accounts for teammate interactions that take place during gameplay, which may be rather limited. Indeed, many of the opportunities for young athletes to engage in social behavior with peers take place outside the game itself - yet it remains unclear how moral behavior amongst teammates in other sport-related contexts, outside gameplay, may relate to perceptions of task cohesion.

One sport-related setting, where moral behavior may impact perceptions of cohesion, is the locker room. Notably, within the locker room, athletes prepare to engage in collective tasks with one another (e.g., passing), or regroup following a collective outcome (i.e., winning or losing).
Moreover, in contrast to competition and practices that are presumably task-focused and have a high level of adult supervision (e.g., referees, coaches, parents), locker room settings provide potential for a range of positive and negative social processes to occur, both with and without adult supervision. Despite the potential implications of social behavior within the locker room, this specific context has yet to be studied.

\section{Current Study}

Building on the recent findings that in-game prosocial and antisocial behaviors among teammates predict perceptions of task cohesion (Al-Yaaribi and Kavussanu, 2017), the current study tested whether prosocial and antisocial behavior in the locker room related to perceptions of task cohesion. Whereas most moral behavior studies focus only on participants' self-report perceptions of their own behavior towards others, or only on peers' behaviors towards the participant, the current study explored both types of these perceptions as they may show differential associations with task cohesion. Furthermore, since youth athletes' moral behavior may depend on the presence of adults, we assessed participants' perceptions of adult supervision as a control variable. Based on the theoretical underpinnings of the social cognitive theory of moral thought and action (Bandura, 1991), we hypothesized that prosocial locker room behavior would positively predict perceptions of task cohesion, while antisocial locker room behavior would negatively predict perceptions of task cohesion. Although we were interested in exploring whether perceptions of task cohesion were more strongly associated with (a) perceptions of peers' moral behavior towards the participant, or (b) the participants' own moral behavior towards teammates, the exploratory nature of this question precluded us from making specific a priori hypotheses.

\section{Methods}

\section{Participants}

The participants were 238 male youth ice hockey players that ranged in age from 8 to 14 years old $(M=10.75, S D=1.67)$, and were primarily Caucasian (87\%). On average, participants reported spending 3.97 hours per week in the locker room $(S D=1.93)$. The participants also reported having considerable 
experience playing ice hockey $(M=5.97$ years, $S D$ $=2.03)$, and had spent an average of 3.24 years $(S D=2.02)$ with their current team.

\section{Measures}

Task Cohesion. To measure perceptions of task cohesion, the current study utilized the task cohesion subscale of the Child Sport Cohesion Questionnaire (Martin et al., 2012), which asked participants about their feelings toward their most recent team (e.g., "In games, we all get along well"). Participants responded to the 7-item instrument using a 5-point Likert-type scale ranging from 1 (strongly disagree) to 5 (strongly agree). This instrument has been demonstrated to be valid (Martin et al., 2013).

Prosocial and antisocial behavior. To assess perceived prosocial and antisocial behavior, the current study utilized a modified version of an instrument used by Galliger et al. (2009) to assess moral behavior on the school bus. Specifically, this instrument captures participants' perceptions of how often they are prosocial/antisocial to peers as well as how often they feel that peers are prosocial/antisocial to them. Originally, this instrument distinguished between moral behavior directed to/from girls and boys, but our all-male sample made it necessary to drop the items pertaining to behavior to/from girls. The four-item adapted instrument included two items to assess participants' views of how often their teammates behaved prosocially/antisocially towards them in the locker room (instead of on the school bus), as well as two items for how often they behaved prosocially/antisocially towards their teammates (e.g., "In the locker room, how often were you kind or nice to your teammates?"). Respondents answered using a 4-point Likert-type scale ranging from 1 (never) to 4 (all the time).

This instrument was selected over other sport-specific scales (e.g., Kavussanu and Boardley, 2009) because the other scales have only been validated for older athletes. The selected instrument is age-appropriate and has been validated for use in research examining moral behavior in a similarly aged sample and in a comparable context (i.e., school bus). An additional strength of the chosen instrument is that it is designed to capture perceptions of both the participant's behaviors as well as peers' behaviors, which enables us to disentangle which perceptions have a stronger association with task cohesion.

Adult supervision. Five items were designed specifically for this study to assess the participants' perceptions of the amount of adult supervision in the locker room (i.e., before and after games / before and after practices). Four questions asked about a specific situation (e.g., "When you were in the locker room after practice, how often was there an adult supervising the team's behavior?"), while the fifth item asked about time spent in the locker room without supervision, and was reverse scored (i.e., "How often were you and your teammates in the locker room without any adult supervision?"). Participants responded to these items using a 5point Likert-type scale ranging from 1 (never) to 5 (all the time).

\section{Procedure}

Before the study was conducted, ethical approval was attained by the Human Subjects Review Board from the authors' institution. Parents of youth ice hockey players were recruited through a summer hockey camp mailing list (i.e., child attended the camp during the previous summer). We sent an e-mail to parents regarding the details of our study and the opportunity to have their child participate. Parents were given an opportunity to review the content of the questionnaires and provided informed consent by clicking a box on the online survey. If parental consent was given, the following screen clearly instructed the parents to give the child privacy for the duration of the process. Youth participants were then given an opportunity to provide informed assent. Data were collected near the end of the typical ice hockey season, though some players' season may have already ended. Participants were incentivized by being entered into a random drawing for one free week of the hockey camp for the following summer.

\section{Results}

\section{Preliminary Analyses}

Missing data were deemed to be completely at random (Little, 1988), therefore, missing values for scale-scored variables were replaced using an expectation-maximization algorithm. The task cohesion and adult supervision scales demonstrated internal reliability $(\alpha \prime s=.89$ and .90 , respectively). The prosocial and antisocial subscales were single 
items; therefore, reliabilities were not calculated. The data were normally distributed for all study variables (i.e., skewness and kurtosis were all < $|1.0|$ ); however, participants' report of their own antisocial behavior was somewhat positively skewed (i.e., skew $=.95, S E=.15$ ). We performed a square root transformation and repeated analyses both with and without the transformed variables. Because the pattern of results was similar, untransformed findings were retained for ease of interpretation.

Table 1 illustrates bivariate correlations from key study constructs. Notably, older athletes reported having less frequent adult supervision in the locker room, and adult supervision was positively associated with prosocial behavior and inversely associated with antisocial behavior.

\section{Main Analyses}

Recall that we expected moral behavior in the locker room to be associated with perceptions of task cohesion. To test this hypothesis, we conducted a three-model hierarchical regression analysis (see Table 2). Perceptions of participants' own moral behavior were entered separately from perceptions of peers' moral behavior so that we could identify the amount of variance in task cohesion that was uniquely explained by each aspect (i.e., $\Delta R^{2}$ ). In the first model, we controlled for age and adult supervision, in which we found that adult supervision was significantly positively associated with task cohesion. In the second model, we added perceptions of the participants' own prosocial and antisocial behavior towards teammates, finding that perceptions of athletes' own prosocial behavior was positively associated with task cohesion. In our final model, we added perceptions of peer moral behaviors. The findings indicate that, above and beyond the effects of the variables entered in the first two models, perceptions of peer prosocial behavior were moderately positively associated with task cohesion, and perceptions of peer antisocial behavior were moderately negatively associated with task cohesion. Moreover, upon entering peer-behavior variables in this final model, selfreported prosocial behavior was no longer significantly associated with task cohesion. Whereas models one and two accounted for a small amount of total variance (i.e., $10 \%$ and $3 \%$ ), adding the perceptions of peer moral behavior in model three accounted for additional $19 \%$ of the variance in task cohesion - increasing the total variance explained to $32 \%$.

\begin{tabular}{|c|c|c|c|c|c|c|c|c|}
\hline \multirow{2}{*}{\multicolumn{9}{|c|}{ Means, Standard Deviations, and Correlations $(N=238)^{\text {Table } 1}$}} \\
\hline & & & & & & & & \\
\hline Variable & $M$ & $S D$ & 1 & 2 & 3 & 4 & 5 & 6 \\
\hline 1. Task Cohesion & 3.71 & 0.74 & & & & & & \\
\hline $\begin{array}{l}\text { 2. Self Prosocial } \\
\text { Behavior }\end{array}$ & 3.46 & 0.60 & $.26^{* *}$ & & & & & \\
\hline $\begin{array}{l}\text { 3. Self Antisocial } \\
\text { Behavior }\end{array}$ & 1.30 & 0.47 & $-.19^{* *}$ & $-.45^{* *}$ & & & & \\
\hline $\begin{array}{l}\text { 4. Peer Prosocial } \\
\text { Behavior }\end{array}$ & 3.06 & 0.69 & $.50^{* *}$ & $.41^{* *}$ & $-.27^{* *}$ & & & \\
\hline $\begin{array}{l}\text { 5. Peer Antisocial } \\
\text { Behavior }\end{array}$ & 1.60 & 0.61 & $-.44^{* *}$ & $-.26^{* *}$ & $.47^{* *}$ & $-.57^{* *}$ & & \\
\hline 6. Adult Supervision & 3.01 & 0.69 & $.31^{* *}$ & $.20^{* *}$ & $-.27^{* *}$ & $.28^{* *}$ & $-.18^{* *}$ & \\
\hline 7. Age & 10.75 & 1.67 & -.12 & $-.19^{* *}$ & $.14^{*}$ & .01 & .00 & $-.23^{* *}$ \\
\hline Note. & $\begin{array}{l}.01 ; * * \\
\text { fer spe }\end{array}$ & $\begin{array}{l}<.00 \\
\text { ically }\end{array}$ & $\begin{array}{l}\text { Adult } \\
\text { the lo }\end{array}$ & pervisi & $\begin{array}{l}\text { and } m c \\
\text { vironm }\end{array}$ & $\begin{array}{l}\text { l behav } \\
\text { at. }\end{array}$ & & \\
\hline
\end{tabular}


Table 2

Summary of Hierarchical Regression Models Predicting Task Cohesion

\begin{tabular}{|c|c|c|c|c|c|c|c|c|c|c|c|c|}
\hline \multirow{2}{*}{$\begin{array}{l}\text { Independent } \\
\text { Variable }\end{array}$} & \multicolumn{4}{|c|}{ Model 1} & \multicolumn{4}{|c|}{ Model 2} & \multicolumn{4}{|c|}{ Model 3} \\
\hline & $\beta$ & $S E$ & $\begin{array}{c}t- \\
\text { Value }\end{array}$ & $s r$ & $\beta$ & $S E$ & $\begin{array}{c}t- \\
\text { Value }\end{array}$ & $s r$ & $\beta$ & $S E$ & $\begin{array}{c}t- \\
\text { Value }\end{array}$ & $s r$ \\
\hline Age & -.02 & $\begin{array}{l}.0 \\
3\end{array}$ & -0.78 & .05 & -.01 & $\begin{array}{l}.0 \\
3\end{array}$ & -0.29 & .02 & -.04 & .03 & -1.61 & .09 \\
\hline $\begin{array}{l}\text { Adult } \\
\text { Supervision }\end{array}$ & $.32^{* *}$ & $\begin{array}{l}.0 \\
7\end{array}$ & 4.64 & .29 & $.27^{* *}$ & $\begin{array}{l}.0 \\
7\end{array}$ & 3.85 & .24 & $.17^{*}$ & .06 & 2.67 & .15 \\
\hline $\begin{array}{l}\text { Self Prosocial } \\
\text { Behavior }\end{array}$ & & & & & $.23^{*}$ & $\begin{array}{l}.0 \\
8\end{array}$ & 2.68 & .16 & .07 & .08 & 0.78 & .04 \\
\hline $\begin{array}{l}\text { Self Antisocial } \\
\text { Behavior }\end{array}$ & & & & & -.07 & $\begin{array}{l}.1 \\
1\end{array}$ & -0.60 & .04 & .16 & .11 & 1.44 & .08 \\
\hline $\begin{array}{l}\text { Peer Prosocial } \\
\text { Behavior }\end{array}$ & & & & & & & & & $.33^{* *}$ & .08 & 4.69 & .22 \\
\hline $\begin{array}{l}\text { Peer Antisocial } \\
\text { Behavior }\end{array}$ & & & & & & & & & $-.32^{* *}$ & .09 & -3.58 & .20 \\
\hline$\Delta R^{2}$ & & & - & & & & 3 & & & & & \\
\hline Total $R^{2}$ & & & 10 & & & & 13 & & & & & \\
\hline Model F & & & $.58^{* *}$ & & & & $94^{* *}$ & & & & $84^{* *}$ & \\
\hline
\end{tabular}

Note: Adult supervision and moral behaviors refer specifically to the locker room environment. $s r=$ Semipartial correlation. ${ }^{*} p<.01 ;{ }^{* *} p<.001$.

\section{Discussion}

The purpose of the current study was to extend our understanding of moral behavior among teammates in the locker room setting, which may relate to perceptions of task cohesion in youth athletes. We tested two hypotheses regarding moral behavior among youth ice hockey teammates in the locker room: (a) that prosocial behavior would positively predict task cohesion, and (b) that antisocial behavior would negatively predict task cohesion. The results revealed that moral behavior in the locker room was indeed associated with perceptions of task cohesion, but this was only true for athletes' perceptions of their peers' moral behavior and not perceptions of their own behavior towards peers. Specifically, we found that peer prosocial behavior was positively related to perceptions of task cohesion, while peer antisocial behavior was negatively related to perceptions of task cohesion, thus highlighting potential consequences of peer social interactions on perceptions of group unity. Based on a concurrent study design, these findings align with Carron et al.'s (2012) assertion that supportive teammate behaviors can promote task cohesion, as well as the recent finding that intrateam conflict (e.g., criticizing teammates) is 
inversely associated with task cohesion (McLaren et al., 2017).

The finding that perceptions of peer behaviors were significantly associated with task cohesion whereas athletes' perceptions of their own behaviors were not, is novel and holds implications for how sport psychology researchers may assess moral behavior in sport. Whereas popular moral sport behavior scales typically only assess participants' self-reported behaviors, Al-Yaaribi and colleagues (2016) recently shed light on the consequences of teammates behavior on the recipient. The current findings further underline the importance of considering both aspects of behavior as they may have unique associations with related psychosocial constructs. Indeed, building on recent findings that teammates' moral behaviors predict task cohesion (Al-Yaaribi and Kavussanu, 2017), the current findings extend understanding to youth sport settings, and indicate that how others treat the individual may be a more salient indicator of the individuals' affective assessment of the group environment.

Pertaining to our understanding of how youth come to form perceptions of team cohesion, it should first be re-emphasized that task cohesion, as operationalized in sport psychology, entails both perceptions of how unified the group is on its collective task, as well as affective evaluations of the individuals' involvement in the task (Carron et al., 1985). Although the construct of cohesion, and how it is defined, has been extensively discussed (Carron and Brawley, 2000), the current findings provide an early indication that youth athletes' perceptions of cohesion are largely drawn from other in-group members' behaviors toward them, rather than their own behaviors toward other members. Additional research in adult athletes may be able to better inform our understanding of how perceptions of cohesion are drawn and identify more specific antecedents.

\section{Limitations and Future Directions}

When assessing group perceptions such as cohesion, it is ideal to sample from intact teams to disentangle the individual-level variance from the variance which occurs at the group-level (i.e., multilevel analyses; Carron and Brawley, 2000). As such, it is prudent to sample complete sport teams in future research, to get accurate perceptions of group-level cohesion (see Benson et al., 2016). Given evidence that perceptions of cohesion may be linked to team performance (Benson et al., 2016), it is also recommended that future research control for team performance. Similarly, because moral behavior differs between youth and adult sport, an important next step would be testing these effects in older samples (Graupensperger et al., 2018). Specifically, recent research has shown that in youth sport, prosocial behavior towards teammates is related to less antisocial behavior towards members of opposing teams, while in adult sport, prosocial behavior towards teammates is associated with greater antisocial behavior towards teammates (Graupensperger et al., 2018). As such, older athletes may base perceptions of task cohesion more on the unity towards the collective task and less on their affective feelings that are presumably more closely tied to moral teammate behavior.

An additional limitation to the current study is that, despite use of a directional regression-based approach, we acknowledge that the link between moral behavior and task cohesion could to be reciprocal. In future studies cross-lagged temporal designs can be used to investigate the directionality of the effect, to improve our understanding of the nature of this association. Lastly, we note that although the current study represents a key initial step, Eys and Brawley (2018) have recently made a call for research that gains a deeper understanding of this association, such as testing whether this association is mediated by other variables (e.g., is this association explained by a third variable such as enjoyment or anger; Al-Yaaribi and Kavussanu, 2018) and identifying moderators of this association (e.g., is this association stronger in athletes who have a collectivist orientation; Donkers et al., 2016).

\section{Conclusions}

Coaches and other stakeholders of youth sport teams that are interested in building team chemistry should consider behaviors that take place when members spend time together in all group settings. When youth participate in sport, they are indeed exposed to an entire package of social experiences that extend well beyond gameplay. Whereas a competition or practice may 
only be an hour or so in duration, a young athlete may be surrounded by teammates while traveling to and from practices and games, while spending time around the sporting venue, and notably, in the locker room before and after gameplay.
Through further research, coaches or practitioners could potentially leverage this time to build team cohesion as well as other forms of peerconnectedness to further enrich the youth sport experience.

\section{Acknowledgments}

The first author is supported by the National Center for Advancing Translational Sciences of the National Institutes of Health; Award number TL1TR002016

\section{References}

Al-Yaaribi A, Kavussanu M. Consequences of prosocial and antisocial behaviors in adolescent male soccer players: The moderating role of motivational climate. Psychol Sport and Exerc, 2018; 37: 91-99

Al-Yaaribi A, Kavussanu M, Ring C. Consequences of prosocial and antisocial behavior for the recipient. Psychol Sport Exerc, 2016; 26: 102-112

Al-Yaaribi A, Kavussanu M. Teammate prosocial and antisocial behaviors predict task cohesion and burnout: The mediating role of affect. J Sport Exerc Psychol, 2017; 39: 199-208

Bandura A. Social cognitive theory of moral thought and action. In: Handbook of Moral Behavior and Development. Vol 1, 45-103; 1991

Benson AJ, Bruner MW. How teammate behaviors relate to athlete affect, cognition, and behaviors: A daily diary approach within youth sport. Psychol Sport Exerc, 2018: 34: 119-127

Benson AJ, Šiška P, Eys M, Priklerová S, Slepička P. A prospective multilevel examination of the relationship between cohesion and team performance in elite youth sport. Psychol Sport Exerc, 2016; 27: 39-46

Bruner MW, Eys MA, Wilson KS, Côté J. Group cohesion and positive youth development in team sport athletes. Sport Exerc Perform Psychol, 2014; 3: 219-227

Carron AV, Brawley LR. Cohesion: Conceptual and measurement issues. Small Gr Res, 2000; 43: 726-743

Carron AV, Eys MA, Martin LJ. Cohesion. In: Tenenbaum G, Eklund RC, eds. Measurement in Sport and Exercise Psychology. Champaign, IL: Human Kinetics, 411-422; 2012

Carron A, Widmeyer WN, Brawley L. The development of an listrument to assess cohesion in sport teams: The Group Environment Questionnaire. J Sport Psychol, 1985; 7: 244-266

Donkers JL, Martin LJ, Evans MB. Psychological collectivism in youth athletes on individual sport teams. Int J Sport Exerc Psychol, 2016; 0: 1-15

Eys MA, Brawley LR. Reflections on cohesion research with sport and exercise groups. Soc Personal Psychol Compass, 2018; 12: 1-15

Eys M, Loughead T, Bray SR, Carron AV. Development of a cohesion questionnaire for youth: The Youth Sport Environment Questionnaire. J Sport Exerc Psychol, 2009; 21: 390-408

Graupensperger S, Jensen CJ, Evans MB. A meta-analytic review of studies using the Prosocial and Antisocial Behavior in Sport Scale: Associations among intergroup moral behaviors. Sport Exerc Perform, 2018; 7: 186-204

Galliger CC, Tisak MS, Tisak J. When the wheels on the bus go round: Social interactions on the school bus. Soc Psychol Educ, 2009; 12: 43-62

Kavussanu M, Boardley ID. The Prosocial and Antisocial Behavior in Sport Scale. J Sport Exerc Psychol, 2009; 31: $97-117$

Kavussanu M, Stanger N. Moral behavior in sport. Curr Opin Psychol, 2017; 16: 185-192

Little RJA. A test of missing completely at random for multivariate data with missing values a test of missing 
completely at random for multivariate data with missing values. J Am Stat Assoc, 1988; 83: 1198-1202

Martin LJ, Carron AV, Eys MA, Loughead TM. Development of a cohesion inventory for children's sport teams. Gr Dyn Theory, Res Pract, 2012; 16: 68-79

Martin LJ, Carron AV, Eys MA, Loughead TM. Validation of the child sport cohesion questionnaire. Meas Phys Educ Exerc Sci, 2013; 17: 105-119

McLaren CD, Newland A, Eys M, Newton M. Peer-initiated motivational climate and group cohesion in youth sport. J Appl Sport Psychol, 2017; 29: 88-100

\section{Corresponding author:}

\section{Scott Graupensperger}

The Pennsylvania State University

Address: 276 Rec Hall, University Park, PA, 16801, USA

Phone: (541) 948-3325

E-mail: Sag40@psu.edu 